\title{
Development of Humanitarian Values in Competence-Oriented Educational Model
}

\author{
Anna V. Shutaleva, ${ }^{*}$, Eugenia V. Ivanova ${ }^{1}$, Eugenia Putilova ${ }^{2}$, Elena V Melnikova ${ }^{1}$, Olesya V. Kuznetsova ${ }^{1}$, Yulia V. \\ Tsiplakova ${ }^{1}$ \\ ${ }^{1}$ Ural Federal University, Ekaterinburg, Russian Federation \\ ${ }^{2}$ Ural Federal University, Nizhny Tagil, Russian Federation
}

\begin{abstract}
Changes in modern education, as a rule, are associated with changes that occur in various social spheres. The society in its current state has acquired a flexible structure, takes into account the needs and desires of the individual, which realizes the freedom of choice. Modern people need skills of cultural communication and a certain amount of knowledge about the world, but their significance is pretty limited. This leads to the investigation of current problems of forming and development of humanitarian values in the competence-oriented educational model in this article. The main problem is that education becomes an algorithm, a set of instructions for performing a certain action. Today this problem is felt not only by humanities researchers but also by those natural scientists that are engaged in fundamental theoretical research. The investigation of the problem of values in the modern competency-oriented model of education allows one to understand education as a cultural and historical form of the creation and development of essential human forces, actualizes the search for new, humanitariananthropological, methodological and theoretical guidelines that would make it possible to fully take into account the personal potential of student in the educational process.
\end{abstract}

\section{Introduction}

There are general cultural competencies in modern educational standards of Russia, which should contribute to the formation of a self-sufficient personality. The general cultural competencies are present in all bachelor education standards of Russian Federation; however, there is the fact that humanitarian competencies are perceived not as intrinsic in nature, but purely utilitarian and applied. General cultural competencies define the ability to communicate in verbal and written form in Russian and foreign languages for solving problems of interpersonal and intercultural interaction and the ability to work in a team, tolerantly perceiving social, ethnic, confessional and cultural differences. The same applies to the competence of using the basics of economic and legal knowledge in various spheres of life.

General cultural competencies of the ability to use first-aid methods, methods of protection in emergency situations relate to the notion of the value of human life, reflects the technical aspect of the attitude towards it. In essence, only three general cultural competencies can be called humanitarian: the ability to use the basics of philosophical knowledge to form a worldview; the ability to analyze the main stages and patterns of historical development of the society that informs one's civic position; aptitude for self-organization and selfeducation. What is the reason for this attitude toward socio-humanitarian skills and sciences? What is the reason for this reductionist approach to sociohumanitarian skillset? Why are humanities themselves perceived as just a set of useful techniques supplementing other graduate skills?

The main reason for this is the orientation of Russia toward economic rationality bordering on economic utilitarianism, which strives to measure everything in terms of rates of economic growth and profit. Thus, the strategy of scientific and technological development of the Russian Federation, signed by the President, says that in the next 10 to 15 years, the priorities of the scientific and technological development of the Russian Federation should be placed on those areas that will yield scientific and technical results and enable the creation of technologies that will form the basis for innovative development of domestic product and service markets as well as ensure Russia's stable position in the foreign markets. The strategy of scientific and technological development of the Russian Federation enumerates the directions of the country's development, like digital technologies, clean energy, high-tech health care, the transition to highly productive and eco-friendly agriculture and aquaculture technologies, counteraction to terrorism and extremism, achieving better cohesion between Russia's constituent territories, the possibility of an effective response of Russian society to great challenges that would take into account the interaction of man and nature, man and technology, social institutions

Corresponding author: a.v.shutaleva@urfu.ru 
at the present stage of global development, including applying methods of humanities and social sciences.

Therefore the question arises, what can humanities give to the world? With respect to education, the answer is quite simple and trivial: it is the development of critical thinking, understanding, and initiative. However, people who are striving for economic growth will struggle with the humanities and art as a component of fundamental education. Critical thinking creates people eager to know themselves and the world in which limits and conventions are subjected to constant revision, where Socratic truth that "knowledge itself is not the mind" is carried out. Another major aspect of humanities is the understanding that includes experience and reflection.

In modern Russian realities, it is problematic to instill critical thinking and develop students' understanding skills due to two main reasons.

First, there is a rigid economy, especially in the humanities. The product yielded by humanities does not lend itself to the measurement system applicable to the natural sciences, hence, the conclusion is made about the irrationality of investing in the sciences of understanding and, moreover, about the possibility of reducing funding to this sphere. Here it is worth mentioning the ongoing optimization of the educational process, taking place in the system of higher education in Russia, leading to a reduction in the teaching staff, the unification of students from different faculties in lecture and seminar classes. The size of the audience is important in teaching, especially in teaching critical thinking, hermeneutics. Indeed, in the short term, it is possible to abandon humanitarian disciplines in curricula, but, in our view, this will lead to the formation of one-sidedly educated individuals. The quality of life consists of many factors and the main factor is the satisfaction of the cultural and spiritual needs of a person, their psychological and social comfort. It is for this aspect of social development that the humanities are responsible.

Secondly, there are changes in pedagogical technologies towards formal verification of knowledge, not skills, which, in fact, is the continuation of the first point. State standards of higher education in Russia are aimed at making a unique specialist of every student through providing a large number of optional study subjects they can choose from. The form of the final evaluation is chosen by the university - the choice is between a traditional exam or testing. However, disciplines that form general cultural competences are increasingly being given to independent test control.

This means focusing on "training" for the test, passive mastering, memorization. On the one hand, there is the question of different scales of measurements in the humanities and natural sciences. On the other hand, there is the fact that the goals of the state educational standard that concern the formation of competencies associated with the philosophical foundations of the formation of the worldview, are not only not achieved, but simply not taken into account at all.

\section{Purpose of the Study}

The purpose of the article is the study of current problems of forming and development of humanitarian values in the competence-oriented educational model.

\section{Research Methods}

The theoretical and methodological basis of this investigation is studying of key characteristics of the educational system in modern society [1-4], of the social and philosophical aspects of the problems of tolerance in the educational space [5-6]. The methodological basis of the study includes an analysis of the Federal State Educational Standard of Higher Education in the field of education and the strategy of scientific and technological development of the Russian Federation [7- 9]. The theoretical basis consists of scientific philosophical works [10-16] and researchers in the field of formation of competences of the education process [17-20].

\section{Findings and Discussion}

\section{The problem of values in modern education}

The society of large cities of the beginning of the third millennium is a society of competition. In this competition, the most diverse individual spiritual needs are satisfied. Opposition and extremes from a certain time have become only "aesthetic categories". For example, Sloterdijk called such a state of things loss of differentiation by subsystems [10].

The systematic approach has long been simplified and reduced to a functional approach to competencies [10]. If a person has a toothache, he goes to the dentist. If the leg is ill - it is necessary to the orthopedist, and if someone started the world sorrow, he goes to the guru. Everyone has his own: for education - school, for money-work and bank loans. If someone does not like the social situation at all - he either participates in the protest movement or leaves for Ibiza. The development of needs has reached such an extent that virtually any most exotic need will find its addressee in modern society. Almost everything can be ordered in the modern world. Sloterdijk sees difficulty only with the order of "great love" [10].

The assertion of J. Lipovecki that socialization has become soft in our day also makes sense [11]. Everywhere there are fewer collective prescriptions and responsibilities, more opportunities for personal choice of direction of movement, more models for identification in society. Authoritative channels disseminating information also become institutions of socialization, influence and knowledge transfer. Data affecting the institutions of tradition, religion, morality are complemented by the impact of information flows through modern media.

At the same time, K. Wolf believes modern socialization is contradictory [12]. On the one hand, people are really serious about their individual lives, and 
on the other hand, they continue to be in social conditions that they can not control. Education, in our opinion, can reconcile these contradictions, believing a person to be active and free, renouncing authoritarian methods, focusing more on worldview diversity and pluralism.

The sphere of information forms a special world in which there is a person today. M. Castells shows the potential of the Internet as a means of ensuring freedom, high productivity, and communication [13, 14]. And indeed, in a network, a person can now realize himself in dozens of different ways. The possibilities of Web 3.0 offer him the most diverse options - from all kinds of self-actualization in the game to paying bills, getting important and necessary information, communicating with colleagues and close ones in the space. The further development of technologies promises the interpenetration of virtual and real life even closer. It is obvious that modern people do not just spend time on the Internet. They are motivated not only by entertainment. The modern generation of people who grew up together with the network, along with entertainment goals in the network, increasingly appreciate the resources of the world wide web of learning opportunities. Learning in a bizarre way is combined with entertainment, informal approach, imaginative, bright, author's informal presentation. A certain place in online discussions is also occupied by clarification of value differences.

The problem of values is most vividly postulated in the philosophy of neo-Kantianism. Rickert defined values as lying outside the field of objects within and outside the field of subjects, as forming an independent "kingdom". In the contradiction between reality and values, Rickert saw the world problem [15]. Private science is successfully engaged in the cognition of reality, and only philosophy poses a problem of values. The values form the sphere of culture.

Hardly after Rickert, it is an exaggeration to say that education as an attempt to improve a person is always guided by values. This value initiative of the NeoKantians in connection with the issues of education was picked up by various anthropological schools. Philosophical anthropology is focused on the plasticity of human nature, the understanding that a person does not have a certain essence and a person must create himself and can only exist by creating his second natureculture.

Globalization and virtualization, constant involvement in the information sphere lead to overcoming distances and influencing the person of new, constantly discovered social and cultural phenomena. The value sphere is deprived of uniformity and visibility; it also manifests differences, diversity, complexity. In this environment, the fundamental knowledge that forms stable representations of the individual inevitably loses its appeal. In a world in the center of which there is a world web, knowledge is acquired either directly in the activity itself, or directly in the process of preparing for it. Wolf identifies four pillars in education and education: to learn knowledge, learn to act, learn to live together peacefully, and learn to be [12].
At the same time, the acquisition of knowledge in constant dynamics through the global information network remains the main source not only of information but of knowledge and skills. It is important to emphasize that in this situation, not only the role of academic education as a way of transferring knowledge is reduced.

\section{The essence of the modern competency- oriented model of education}

The transition of the Russian education system to a competency-oriented model is due to a number of reasons. The first is Russia's entry into the Bologna Process, the main goal of which is the creation of a single European educational, research and cultural space. To achieve this goal, it became necessary to harmonize national educational and professional standards, to ensure the transparency of the educational systems of the countries participating in the Bologna process and create a common language for describing the results of education.

The focus of standards and educational programs on the achievement of the agreed-upon goals of education, thus, allows ensuring their transparency and the ability to compare qualifications in the field of vocational education [6, 8]. Competencies are precisely the methodological tools and the agreed-upon language that describes the results of education and ensures the internationalization and compatibility of the education market and the labor market.

It should be emphasized that the term "competence" is not a synonym for knowledge, skills, and habits. The results of education, described in the language of competencies, are understood as new types of results that go beyond the scope of professional knowledge, skills, and habits.

Traditionally, qualification characteristics of a graduate and qualification of a specialist meant the correspondence of educational goals to the requirements of the profession and had a standardized scope of application. The emerging new economic structure, the knowledge economy, requires a new, innovative person who has a broad outlook and is able to perform complex analytical tasks, to work in conditions of uncertainty, within rapidly changing and aging context. To solve complex problems, private knowledge and skills are insufficient; their integration into complex psychological formations called competencies is required.

Most Russian and foreign researchers of the competency approach, first, emphasize its activityoriented, practical orientation, and, secondly, pay attention to the concept competence.

Competence is understood as a general ability and willingness to use the knowledge, skills, and habits acquired in the course of training, to make decisions independently in conditions of uncertainty, to take responsibility for their implementation. At the same time, competence is an open system, a set of interacting components that are actualized and enriched in activity as the real vital problems encountered by the person arise. 
The concept competence is understood as an integrated characteristic of the qualities of a person, the result of training a person to perform activities in certain areas. If competence is a parameter of a social role, then in the personal sphere competence is manifested as competency, i.e. the person's compliance with the place occupied, the ability to carry out activities in accordance with social requirements and personal expectations.

It is hardly possible to teach competency. People can become competent only by themselves, solving vital tasks, testing various models of behavior, choosing those that are more in line with their claims, tastes, value orientations. Competency, therefore, appears as a complex synthesis of not only cognitive and operationaltechnological components but also motivational, ethical, social, behavioral components $[19,20]$. Thus, competencies are potential opportunities, competency realized, actualized competences, the result of a person's self-development, his personal growth, self-organization.

The transition to the competency-oriented model requires the shift in the focus of educational programs from the development of subject knowledge and the memorization of information to the development of personal and universal competencies, the so-called skills of the 21 st century.

The second reason for the transition to a competency model is a change in the understanding of education and its goals. A new type of "digital" civilization, as noted in the report "Russia 2025: from human resources to talents" of the international Boston Consulting Group due to the increasing adoption of algorithms and computer solutions, causes a reorientation of labor market needs for "human in man" on the creative principle, for the cultural, moral aspects of interaction everything that machines can not realize [9].

The Federal Law "On Education in the Russian Federation" reflects the world trend in understanding education as 1) a unified purposeful process of education and training; 2) a socially significant public service that is carried out in the interests of the individual, family, society, and state; 3) the complex of acquired knowledge, skills, values, experience and competencies of a certain amount and complexity [8].

\section{The contextual paradigm in modern pedagogy as new technology enabling developing of students cognitive activities}

In the Russian didactic traditions, two approaches to understanding the assimilation of knowledge, skills, and habits were carried out. The first is an associative-reflex theory associated with the implementation of such elements of activity in the process of teaching students, a plan, execution, control. The second is an activityoriented approach, which is based on the concepts of action and task. Its goal is not the reproduction of memorized knowledge, but the ability to creatively solve problem situations arising in the solution of educational and cognitive tasks. Without denying the value of these approaches in the implementation of various learning goals, the contextual paradigm is becoming more popular in modern technologies of teaching students.

It should be noted, that the focus of pedagogical technologies on the future acquisition of professional skills is not a new topic. The modern pedagogical technologies pay more and more attention to the contextual process, not just the professionally oriented learning process.

The very concept of "context" is polysemic. It serves as the formative concept in the implementation of new requirements for the professional training of future specialists. The internal content of the context is the motivation of the individual not to assimilate abstract knowledge in general and to receive positive assessments for the application to the diploma, but to obtain practical knowledge and skills in the creative solution of applied problems in any sphere of the future professional profile. That is why the concept of context is used, that this knowledge is not one-sidedly oriented toward "pure practice," and this is not "cultivation" or "narrow" specialists. It is necessary to remember the legacy of F. Bacon, who even in the old times of the Modern era spoke of both "luminiferous" and "fruitful" sciences - they are effective only in close collaboration. There is the socio-cultural space, in which the young specialist will operate, various situations of ethical, legal, and purely professional nature.

The dialectical relationship of the internal and the external context should be taken into account in the development of all parameters of the application of the contextual paradigm. Strategies for accomplishing the dialectical unity of external and internal factors of determination and obtaining the skills of the future profession are one of the basic conditions for implementing the contextual paradigm, without which the young specialist may have a disappointment with his choice.

Dissatisfaction in the choice of profession, the realization of the inability to bring element of creativity into one's work leads to a large number of losses suffered by both the society and the individual who feels discouraged from self-perfection and improving skills, which leads to reduction in productivity and makes very likely the onset of professional deformation. Therefore, in the contextual paradigm, great attention is paid to the disclosure, analysis, and implementation of the internal factors of the choice of profession in the future specialist: value orientations, abilities, character qualities, physical characteristics, health status, a degree of self-knowledge, level of reflexive culture. This is how the professional self-consciousness of the student is formed.

External factors that will affect the determination of the choice of profession should include knowledge of the chosen profession, knowledge of the possible places of work and their requirements for the employee, knowledge of educational organizations and the possible places of study, knowledge of the labor market and its prospects. We propose to call this knowledge and its realization in educational technologies, social context. However, the social context should be supplemented by "technological" or "professional" context - the 
assimilation of those types of professional knowledge and skills that are required by the chosen profession.

The prerequisite for the realization of the social context can be the creation of a personal professional perspective by the students.

The main components of it can be designated as follows:

1. The moral value basis of self-determination in the future profession (the need for this profession in society, the "need" of other people to be provided with assistance - not service) along with the spiritual and social prestige of the profession.

2. The definition of the ultimate professional goal and corresponding career strategy, about which entrants, students, and graduates usually think very little.

3. The awareness of personal weaknesses and advantages that help or hinder the achievement of the assigned professional goals (requires working on selfassessment and self-control) that postulates the need for the assistance of professional educators and psychologists in individual cases.

4. Development of professional motivation increasing interest in the future specialty, and preventing disappointment caused by the wrong career choice.

These basic components can be supplemented by others, depending on the strengthening of the moral, legal, psychological aspects of the social context.

One of the prerequisites for the realization of the professional context in the conditions of higher education is to create conditions for the transformation of educational and cognitive activity into professional activity. Three interrelated components in teaching activity are consistently used for this purpose: semiotic, imitative and social. The semiotic component is associated with traditional forms of activity-oriented high-school education: lecture courses, practical and seminar classes, homework, and tests, essays and presentations on given topics. The realization of independent activities, such as preparation for seminars, writing essays, an element of learning and cognition is often present, and there is no element of professional activity. However, if they have not learned to work on themselves, it will be very difficult to do this during their professional activity, while any modern places of work impose numerous demands on the employees requiring them to constantly obtain new knowledge, self-develop and self-educate. The contextual paradigm in education is not only aimed at the present educational and professional activities. The contextual paradigm in education sets the foundation for the future specialist, taking into account the internal and external context of his personal life and the life of the society.

\section{Conclusion}

The goal of education is the development of a person, his intellectual, spiritual, moral, creative, physical and professional characteristics, and a satisfaction of his educational needs and interests. Education is understood as one of the fundamental human rights, but also as an opportunity that allows people to use other rights, develop themselves, and search for their true vocation.

Humanitarian values in education are coming to the forefront:

First, it is the development of individuality, which provides the opportunity for self-organization of life, when a person must be active, be able to take responsibility for one's life.

Secondly, creativity becomes an integral part of the education process. Assimilation of knowledge and skills, solving problems through creativity is one of the main actual features of new people.

As a logical consequence, third, we should note the desire for communication, especially in game form, as the game develops the creative mind. Globalized space is the space of intercultural communication, which education must take into account. Dialogue, orientation to the Other, openness and understanding are the values and challenges facing education today.

And, finally, in the fourth. In the expanded sphere of information and at a high rate of technological development, the impossibility of being tied to work. Refusal of education from fixation in one profession. It is much more important to develop the ability to cooperate, work in a team, and also the ability to innovate. Ability to form spheres of life out of work.

From the point of view of anthropology, modern education, thus, appears as a person-oriented, ensuring the demand for personal potential, recognition of the self-worth of the individual, awareness of its own importance.

An active inclusion of the student in independent activities is a paramount element of contextual education in the formation of the student's readiness for professional self-realization. It should be noted that the training, learning and research activities of the student are closely connected with the educational and sociocultural activities, as social elements of the context.

\section{References}

1. J. Hylen, Open Educational Resources: Opportunities and Challenges (France, Paris, OECD, 2006)

2. P. Blumberg, Innovative Higher Education 34(2), 93-103 (2009)

3. P. Strandbrink, Educational Philosophy and Theory 50(3), 254-269 (2018)

4. A. Petrikova, T. Kuprina, A. Beketova, M. Mishenkova, XLinguae 10(4), 287-303 (2017)

5. V. Stoupel, J. Ingolfsson, Educational Philosophy and Theory 50(6-7), 728-732 (2018)

6. Strategy of innovative development of the Russian Federation for the period up to 2020, retrieved from http://www.garant.ru/products/ipo/prime/doc/70006 $\underline{124 /}$

7. The World Education Monitoring Report (WDMO) for 2016 Education for people and the planet, retrieved

from 
http://unesdoc.unesco.org/images/0024/002457/245 752E.pdf

8. The Federal Law "On Education in the Russian Federation", retrieved from https://fzakon.ru/laws/federalnyy-zakon-ot29.12.2012-n-273-fz/statya-2/

9. Report "Russia 2025: from cadres to talents", retrieved from https://www.bcg.com/enus/default.aspx

10. P. Sloterdijk, H. J. Heinrichs, The sun and death, and Dialogical studies (Frankfurt am Main, 2001)

11. J. Lipovetsky, Era of emptiness. The essay on modern individualism (2008)

12. K. Wulf, Anthropology. A Continental Perspective (Chicago: University of Chicago Press, 2013)

13. M. Castells, The Information Age: Economy, Society and Culture: The Rise of the Network Society (Malden, Oxford: Blackwell Publ. 1996)

14. M. Castells, The Information Age: Economy, Society and Culture: The Power of Identity. (Malden, Oxford: Blackwell Publ. 1997)

15. H.J. Rickert, Science and history: A critique of positivist epistemology (Van Nostrand, 1962).

16. A. Bandura, Social Foundations of Thought and Action: A Social Cognitive Theory (Englewood Cliffs, NJ: Prentice Hall, 1986)

17. L. Beamer, Journal of Business Communication 29(3), 285-303 (1992)

18. O. Muzychenko, European journal of international management 2(4), 418-436 (2008)

19. S. Lester, Higher Education, Skills and Work-based Learning 7(4), 381-393 (2017)

20. D. T. Dugarova, so Starostina, L. V. Cherepanova, International Journal of Applied Engineering Research 11(11), 7318-7325 (2016) 